\title{
Filosofi dan Konsep Dasar Kesehatan Kerja Serta Perkembangannya dalam Praktik
}

\section{Meily Kurniawidjaja*}

\begin{abstract}
Abstrak
Kesehatan kerja merupakan masalah setiap individu karena bekerja dibutuhkan semua orang sebagai sumber pendapatan untuk memenuhi kebutuhan hidup. Sejak lama diketahui bahwa bekerja dapat menyebabkan gangguan kesehatan atau penyakit. Sebaliknya, kesehatan dapat mengganggu pekerjaan. Artikel ini bertujuan memberikan pemahaman tentang konsep, praktik dan manfaat kesehatan kerja bagi para pekerja dan pemberi kerja. Kesehatan kerja seharusnya tidak hanya terfokus pada diagnosis dan pengobatan klinis, tetapi juga mengerjakan rekognisi hazard, penilaian risiko dan intervensi untuk menghilangkan atau meminimalkan risiko. Lingkupnya diperluas untuk mencegah penyakit dengan cara: (1) penempatan pekerja pada pekerjaan/jabatan yang sesuai (fit) dengan status kesehatan dan kapasitas kerjanya. (2) program promosi kesehatan pekerja; (3) perbaikan lingkungan kerja; (4) perbaikan pekerjaan; (5) pengembangan pengorganisasian pekerjaan dan budaya bekerja.; dan (6) surveilans kesehatan pekerja. Indonesia telah meratifikasi konvensi dan rekomendasi ILO yang berhubungan dengan kesehatan kerja. Ada profesional dari multidisiplin dan organisasi profesi melakukan kesehatan kerja di lapangan tersebut, dan banyak pengandil yang lain.
\end{abstract}

Kata kunci: Kesehatan kerja, ahli kesehatan kerja, lingkup kesehatan kerja

\begin{abstract}
Occupational health $(\mathrm{OH})$ is everybody responsibility, because work is human being and decent work is human right, Many work related diseases were documented and stimulated people to do something to overcome it. The objective of this article is to explain the concept, practice and benefit of the occupational health for wokers and employers. The occupational health should not only focus on clinical diagnostic and therapy, but should do hazard recognizing, risk assessment and intervention to eliminate or minimize the risk (risk management method), and widen its scope to prevent diseases by (1) placing the worker in a task adapted to his health status and working capacity; (2) workers' health promotion program;(3) the improvement of the working environment; (4) the improvement of work; and (5) the development of work organization and working cultures; (6) workers health surveillance. Indonesia had ratified ILO conventions and recommendations related to $\mathrm{OH}$. There are professionals from multidiscipline and organizations conduct $\mathrm{OH}$ in the field, and many other $\mathrm{OH}$ stakeholders.
\end{abstract}

Key words: Occupational Health, $\mathrm{OH}$ professionals, scope of $\mathrm{OH}$

*Staf Pengajar Departemen Kesehatan \& Keselamatan Kerja Fakultas Kesehatan Masyarakat Universitas Indonesia 
Kesehatan kerja merupakan masalah semua orang karena bekerja adalah bagian kehidupan dan orang memerlukan pekerjaan sebagai sumber penghasilan yang diperlukan untuk memenuhi kebutuhan hidup. Namun, sejak lama diketahui bahwa bekerja dapat menimbulkan gangguan kesehatan atau penyakit, dan sebaliknya kesehatan dapat mengganggu pekerjaan.

Beberapa kejadian/Evidence di bawah ini dapat memberikan gambaran tersebut. Seorang pengemudi taksi yang duduk di belakang kemudi lebih dari 10 jam setiap hari, menderita nyeri tulang belakang bagian bawah akibat HNP (hernia nucleus pulposus). Setelah menjalani tindakan bedah dan dinyatakan sembuh, ia bertanya kepada manajemen apakah ia diperbolehkan bekerja kembali dan apakah penyakitnya dapat timbul kembali? Tiga dari 12 orang pekerja wanita di pabrik sepatu di diagnosis menderita penyakit kulit akibat kontak dengan bahan perekat. Dokter menganjurkan agar pekerja menghindari kontak dengan bahan perekat tersebut. Manajemen dihadapi dengan masalah mutasi atau penggantian bahan perekat, keduanya bukan hal mudah untuk dilaksanakan. Seorang anak berumur satu tahun keracunan timah hitam. Dokter anak menduga debu timah hitam yang menempel pada baju kerja sang ayah yang bekerja di pabrik beterai mungkin merupakan penyebabnya. Selain itu, cat tempat tidur juga dicurigai telah memajani si anak.

Sehat merupakan hak azazi manusia yang bersifat universal, karena setiap warga negara berhak mendapatkan pekerjaan dan penghidupan yang layak bagi kemanusiaan. ${ }^{1}$ Di Indonesia, hal tersebut diatur dalam peraturan perundang-undangan. ${ }^{2,3}$ Pekerjaan yang layak yang bersifat manusiawi yang memungkinkan pekerja berada dalam kondisi selamat dan sehat, bebas dari kecelakaan dan penyakit akibat kerja. Kesehatan Kerja yang merupakan bagian dari Keselamatan Kerja dan Kesehatan Kerja (K3). K3 (Occupational Safety and Health) (OSH) yang bertujuan agar pekerja selamat, sehat, produktif dan sejahtera. Dengan demikian, produksi dapat berjalan dan berkembang lancar berkesinambungan (sustainable development) tidak terganggu oleh kejadian kecelakaan maupun pekerja yang sakit atau tidak sehat sehingga menjadi tidak produktif. Kejadian kecelakaan kerja diminimalkan oleh upaya Keselamatan Kerja atau Safety, sedangkan kesehatan pekerja dijaga/dipelihara dan ditingkatkan oleh upaya Kesehatan Kerja atau Occupational Health.

Kesehatan Kerja, bertujuan untuk mengenal (rekognisi) hazard kesehatan di tempat kerja, menilai risiko hazard dan melakukan intervensi terhadap risiko, agar menghilangkan atau meminimasi risiko kejadian penyakit.4,5 Di dunia usaha dan dunia kerja, pelaksanaan upaya kesehatan kerja diwajibkan berdasarkan konsep hak azasi manusia yang bersifat universal. Di Indonesia, hal tersebut diatur oleh peraturan perundang-undangan dan prinsip ekonomi pekerja yang sehat, produktif dan sejahtera di samping merupakan aset perusahaan yang paling berharga juga dapat mencegah kerugian (loses).

\section{Sejarah Kesehatan Kerja}

Pada mulanya, kesehatan kerja berkembang dari kesadaran bahwa bekerja dapat menimbulkan gangguan kesehatan atau penyakit akibat kerja yang memerlukan upaya pencegahan. Pada jaman prasejarah, orang Mesir telah mengenal manfaat cadar bagi perlindungan respirasi saat menambang cinabar (red mercury oxide); di Arabia ada catatan tentang efek sinar matahari pada pekerja di tambang raja Solomon. Pada abad pertengahan sebelum abad ke-19, Georgius Agricola (1494-1555) dari Bohemia menemukan pekerja tambang dengan gejala silikosis. Untuk mencegah penyakit tersebut, Dia menganjurkan tentang pentingnya kebersihan udara di lingkungan kerja, dan menulis buku Of Things Metallic; Theophrastus Bombastus van Hohenheim Paracelsus (1493-1541) dari Austria, menyadari hubungan dosis-respons antara kejadian penyakit pada pekerja pengecoran logam dan beratnya penyakit. Hal tersebut telah menjadi dasar perkembangan disiplin ilmu toksikologi. Bernardino Ramazini (1633-1714), seorang professor di Modena, menulis buku yang berjudul A Diatribe on Diseases of Workers yang membahas penyakit yang terdapat di kalangan pekerja. Kepada para dokter ia menekankan agar selalu bertanya kepada pasien tentang pekerjaan mereka. Dia dikenal sebagai 'Bapak Kesehatan Kerja' karena prestasi dan jasanya dalam pengembangan ilmu pengetahuan kesehatan kerja. Pada jaman revolusi industri, Percivall Pott (1766) menyatakan penyakit yang berhubungan dengan pekerjaan, yaitu kanker skrotum yang banyak ditemukan pada pembersih cerobong asap batubara. Sekarang diketahui bahwa penyebabnya adalah senyawa PAHs/polinuklear aromatik hidrokarbon yang terdapat dalam jelaga cerobong. ${ }^{4}$

Banyak upaya kesehatan kerja yang telah dirintis dan tercatat dalam sejarah. Di Eropa, pada abad ke-19, Anthony Ashley Cooper, $7^{\text {th }}$ Earl of Shaftesbury (1801-1885) menurunkan jam kerja dan meningkatkan kondisi kerja bagi pekerja anak dan wanita di tambang, pabrik dan di tempat kerja lainnya; Dr. Thomas Percival (1740-1804) melaporkan tentang pekerja anak di pabrik tekstil; Robert Owen (1771-1858) memberlakukan kondisi kerja yang baik di pabrik tekstilnya. Legislasi di pabrik dimulai oleh Sir Robert Peel Sr. (1788$1850)$; tercatat pula Sadler (1780-1835) yang mendukung perubahan pada parlemen. Dr Thomas Legge (1863-1932) adalah inspektor pabrik yang pertama di Inggris dan penulis buku Industrial Maladies (1934). Beberapa nama yang juga tercatat banyak berperan di bidang kesehatan kerja di negeri mereka antara lain Erisman (1842-1915) di Rusia; dan Hamilton (1869-1970) di Amerika yang banyak meneliti tentang keracunan timah hitam. ${ }^{4}$

Bersamaan dengan perkembangan modernisasi dan industri secara pesat, terjadi perubahan pola penyakit pada populasi umum dan populasi pekerja. Perubahan tersebut terjadi dari penyakit-penyakit infeksi menjadi penyakit yang berhubungan dengan gaya hidup tidak sehat, terutama adalah penyakit pembuluh darah (mis. penyakit jantung koroner dan 
stroke), keganasan, penyakit metabolisme dan penyakit degeneratif otot dan tulang rangka. Beberapa "penyakit modern" yang berhubungan sangat erat dengan gaya hidup tidak sehat tersebut banyak menyerang pekerja, terutama yang bekerja di perkantoran yang kurang aktivitas fisik. Dengan demikian, selain kecelakaan dan penyakit terkait kerja yang menimbulkan kerugian dan menurunkan produktivitas, ternyata penyakit kardiovaskular juga menimbulkan kerugian yang jauh melampaui kerugian yang ditimbulkan oleh KAK/PAK. Gabungan tersebut diperkirakan telah menyebabkan kerugian sebesar 20\% GDP global. Di Indonesia, Survei Kesehatan Rumah Tangga (SKRT) 1995 menemukan bahwa penyakit kardiovaskular merupakan penyebab kematian utama di Indonesia $(24,5 \%)$, lebih tinggi daripada penyakit infeksi $(22,5 \%) .6 \mathrm{Hal}$ serupa ditemukan pula pada populasi pekerja di beberapa perusahaan besar seperti di Pertamina dan PT Indocement Tunggal Prakarsa, Tbk. ${ }^{7,8}$ Oleh sebab itu, pada dekade terakhir ini, upaya kesehatan kerja selain berupaya melindungi pekerja agar tidak mengalami KAK dan PAK, juga melakukan upaya memelihara dan meningkatkan derajat kesehatan pekerja dan kapasitas kerja dengan melakukan promosi kesehatan terutama perilaku hidup.

Batasan "sehat" yang menjadi tujuan Kesehatan Kerja, bukan saja sehat secara fisik, mental dan sosial sesuai yang didefinisikan WHO pada tahun 1948, tetapi juga sehat secara spiritual sesuai definisi yang disempurnakan WHO pada tahun 1984 dan diamanatkan oleh WHA (Wealth Health Assembly) tahun 1999. Definisi tentang kesehatan yang tidak jauh berbeda juga tercantum dalam Undang-undang No.23 tahun 1992 tentang Kesehatan. ${ }^{3}$

Kesehatan adalah keadaan sejahtera badan, jiwa dan sosial yang memungkinkan setiap orang hidup produktif secara sosial dan ekonomis.

\section{_ UU No.23 tahun 1992 tentang Kesehatan, Pasal 1} ayat 1 .

Upaya kesehatan yang mengutamakan upaya kuratif dalam jangka panjang bersifat konsumtif tidak produktif. Dari segi ekonomi, upaya investasi pada orang yang 'tidak atau belum sakit' lebih cost-effective daripada terhadap orang sakit. Paradigma "sehat" yang dicanangkan Departemen Kesehatan RI pada tahun 1998, lebih menekankan upaya promotif-preventif daripada upaya kuratif-rehabilitatif. Prinsip dan paradigma ini berlaku pula pada upaya kesehatan kerja.

\section{Konsep Kesehatan Kerja Makro \\ Kesehatan Kerja di Tingkat Internasional}

Sehat merupakan hak azazi manusia. United Nations Declaration on Human Rights yang dirumuskan pada tahun 1948 di Helzinki menyebutkan bahwa setiap orang mempunyai hak azasi untuk bekerja, bebas memilih jenis pekerjaan dan mendapatkan kondisi pekerjaan yang adil dan membuatnya sejahtera. Pada tahun 1976, dalam United Nations International Covenant on Economic, Social and Cultural Rights kembali menyatakan perlunya kondisi kerja yang sela- mat dan sehat sebagai hak azasi setiap orang Hal ini diakui oleh kelompok negara-negara yang terlibat dalam perjanjian ini. ILO sebagai organisasi pekerja sedunia merumuskan tentang pentingnya tempat kerja yang produktif dan layak (productive and decent work place). ${ }^{1}$

Kesehatan dan keselamatan kerja merupakan masalah dunia. Estimasi Global yang dilaporkan ILO pada tahun 2002 menyebutkan, isu utama bidang K3 berupa 2,2 juta kematian terkait akibat kerja setiap tahun dari 2,8 milyar tenaga kerja di dunia, dengan rincian 270 juta kecelakan kerja, 160 juta penyakit terkait kerja yang menyebabkan kerugian sekitar 4\% dari GDP global (30 triliun US dolar). ${ }^{9}$ Dengan demikian, dalam upaya memenuhi kebutuhan, penanganan K3 telah berkembang secara lebih serius sejalan dengan peningkatan aspek moral minat perorangan, industriawan, dan pemerintah untuk menolong pekerja dari penyakit akibat kerja dan cidera.

Di tingkat dunia, terdapat dua badan yang langsung berkaitan dengan pengaturan kesehatan kerja, yaitu International Labour Organization (ILO) dan World Health Organization (WHO). ILO adalah badan pertama yang dibentuk PBB. Selain mempromosikan keadilan sosial dan hak azasi manusia/pekerja, antara lain memformulasi hak dan standar kerja minimal bagi pekerja, mengatur hubungan kerja dan akibat yang ditimbulkannya, ILO juga memberikan bantuan teknik dalam bidang $\mathrm{K} 3$ dengan menghasilkan konvensi dan rekomendasi yang wajib diratifikasi atau diperundangkan oleh negara peserta PBB. Tidak kurang dari 187 konvensi ILO telah dipublikasikan, termasuk Konvensi ILO No. 155 tentang Occupational Health and Safety, Konvensi ILO No. 161 tentang The Provision of Occupational Health Services to All Employees, ${ }^{1}$ dan Konvensi ILO No. 187 (dan Rekomendasi ILO No. 197) tentang Promotional Framework for Occupational Safety and Health yang baru dipublikasikan pada tahun 2006. ${ }^{10}$ WHO adalah salah satu badan PBB khusus untuk kesehatan yang bertujuan untuk pencapaian derajat kesehatan yang tertinggi bagi semua bangsa di seluruh dunia.

Selain ILO dan WHO, terdapat badan-badan non pemerintah yang mempunyai interest di bidang $\mathrm{K} 3$, antara lain adalah International Commission on Occupational Health (ICOH) dan International Social Security Association (ISSA). Badan-badan pemerintah dan non pemerintah ini meliputi semua aspek K3, termasuk aspek teknik, medik, sosial dan legal, yang mencakup berbagai disiplin ilmu, profesi dan kelompok sosial. Organisasi-organisasi tersebut mempunyai jejaring yang luas, merupakan ajang pertukaran informasi dan pengalaman antar negara. ${ }^{1}$

Di Amerika banyak negara bagian mengatur dengan peraturan perundang-undangan tentang substansi berisiko yang berada di lingkungan tempat kerja, termasuk Environmental Protection Agency (seperti Bapedal di Indonesia) dan OSHA. Sejak tahun 1970 diberlakukan Occuptional Safety and Health Act untuk mengurangi risiko kecelakaan dan penyakit pada pekerja. NIOSH juga mulai aktif pada tahun 1970, bertugas meneliti dan mendidik, dan melakukan evaluasi hazard 
keselamatan dan kesehatan. Beberapa negara bagian mewajibkan pelaporan PTK dan menjalankan program surveilans. ${ }^{1}$

\section{Kesehatan Kerja di Tingkat Nasional}

Undang-undang Dasar 1945 Republik Indonesia Pasal 27 menyebutkan bahwa setiap warga negara berhak mendapatkan pekerjaan dan penghidupan yang layak bagi kemanusiaan. Pekerjaan yang layak adalah pekerjan yang bersifat manusiawi, yang memungkinkan pekerja berada dalam kondisi selamat dan sehat, bebas dari kecelakaan dan penyakit akibat kerja.

PT Jamsostek melaporkan (Desember 2006) bahwa terjadi 95.624 kecelakaan kerja, 1.784 kematian, 8.013 cacat menetap dan kompensasi lebih dari Rp. 222 milyar. Kompensasi ini adalah sebagian dari kerugian langsung dari sekitar 7,5 juta pekerja sektor formal yang aktif sebagai peserta Jamsostek. ${ }^{10}$ Hal tersebut belum menggambarkan keadaan seluruh pekerja Indonesia yang berjumlah sekitar 40 juta di sektor formal, dan 104 juta pekerja di semua sektor. Indonesia belum mempunyai data tentang penyakit akibat kerja. Namun, bercermin pada negara lain di dunia terutama di Asean diyakini bahwa jumlah korban dan kerugian yang timbul akibat kerja tidak sedikit.

Untuk memelihara dan meningkatkan derajat kesehatan pekerja dan kapasitas kerja mereka serta mencegah KAK/PTK, diperlukan kebijakan nasional dengan upaya promotif dan preventif, mereduksi/mengeliminasi faktor risiko. Hal tersebut akan memperbaiki status kesehatan pekerja, kondisi kerja dan lingkungan kerja, dan pada gilirannya reduksi biaya kesehatan serta biaya produksi. Bila upaya perlindungan tersebut gagal maka diberlakukan peraturan perundangan untuk memberikan jaminan kuratif dan rehabilitatif, serta kompensasi bagi pekerja yang menjadi korban kecelakaan kerja atau penyakit terkait kerja (work related diseases).

Upaya-upaya pemerintah mengembangkan dan membudayakan K3, antara lain adalah: Pertama, meratifikasi Konvensi ILO No. 81 tentang Pengawasan Ketenaga kerjaan dalam Industri dan Perdagangan. Kedua, melakukan pembinaan norma perlindungan pekerja yang diwujudkan dalam peraturan K3 yang memuat ketentuan umum K3, standar kerja dan berbagai faktor terkait K3. Mewajibkan majikan memelihara lingkungan kerja dan prosedur kerja yang aman dan sehat. Memberikan pengobatan, rehabilitasi dan kompensasi bagi pekerja yang mengalami kecelakaan dan penyakit akibat kerja. Ketiga, mendukung dan mendorong pelaksanaan K3 secara swakelola dan swadaya, antara lain dengan membentuk Panitia Pembina Keselamatan dan Kesehatan Kerja (P2K3) di perusahaan. Membentuk Pos Upaya Kesehatan Kerja (Pos UKK) bagi usaha mikro, kecil dan menengah (UMKM) terutama sektor informal dengan keterlibatan Puskesmas setempat. Mendukung kegiatan organisasi profesi di bidang K3 yang antara lain meliputi Ikatan Dokter Kesehatan Kerja Indonesia (IDKI), Persatuan Doter Spesialis Okupasi Indonesia (PERDOKI), Asosiasi Hiperkes dan Keselamatan Kerja Indonesia (AHKKI) dan Asosiasi Ahli Keselamatan dan Kesehatan Kerja (A2K3). Keempat, membentuk lembaga tripartit yang mencakup unsur pemerintah, pengusaha dan pekerja.

Di tingkat nasional dikenal Dewan Keselamatan dan Kesehatan Kerja Nasional (DK3N). Anggota dewan terdiri dari 30 orang, unsur pekerja diwakili oleh serikat pekerja/buruh (KSPSI, APKABEL, KSBSI dan FSBDSI), pengusaha oleh asosiasi pengusaha (APINDO). Sektor pemerintah diwakili oleh Departemen Perdagangan, Departemen Pertanian, Departemen Perhubungan, Departemen Kesehatan, Departemen Pekerjaan Umum, Departemen Perindustrian, Departemen Kehutanan, Departemen Energi dan Sumber Daya Mineral, Badan Tenaga Nuklir Nasional. DK3N merupakan organisasi non profit yang berfungsi memberikan masukan kepada Menteri Tenaga Kerja dan Transmigrasi dan organisasi dalam pembinaan norma-norma ketenaga-kerjaan di bidang K3. ${ }^{11}$ Pada awal tahun 2007 ini DK3N telah berhasil merumuskan Visi, Misi, Kebijakan, Strategi dan Program kerja Keselamatan dan Kesehatan Kerja (K3) Nasional. ${ }^{10}$

Peraturan perundang-undangan yang berkaitan dengan kesehatan kerja dan berlaku sampai kini, sebagian besar dikeluarkan oleh Departemen Kesehatan dan Departemen Tenaga Kerja dan Transmigrasi, sebagian lainnya oleh Departemen Energi dan Sumber Daya Mineral, Departemen Perhubungan dan lain-lain. Hal yang penting antara lain meliputi. 1) Undang-undang Dasar 1945 Pasal 28, menyatakan setiap warga negara berhak atas pelayanan kesehatan. 2) Undang-undang No.1 Tahun 1970 tentang Keselamatan Kerja, antara lain menyatakan pemberi kerja wajib memeriksakan kesehatan pekerja awal, berkala dan khusus 3) Undangundang No. 23 Tahun 1992 tentang Kesehatan, dalam Pasal 22 ayat (2) tentang Pelaksanaan Kesehatan Lingkungan Kerja, Pasal 23 ayat $(1,2,3)$ tentang Kewajiban Melaksanakan Kesehatan Kerja, mencakup pelayanan, pencegahan PAK dan syarat kesehatan kerja, serta Pasal 84 tentang Sangsi Pidana Bagi Yang Tidak Melaksanakan. 4) Undang-undang No. 3 Tahun 1992 tentang Jaminan Sosial Tenaga Kerja, antara lain menyebutkan bahwa pemberi kerja wajib memberikan perlindungan biaya kecelakaan, kematian, hari tua dan pemeliharaan kesehatan 6) Undang-undang No.13 Tahun 2003 tentang Ketenagakerjaan, antara lain menyebutkan bahwa pemberi kerja wajib melindungi keselamatan pekerja melalui penyelenggaraan upaya keselamatan dan kesehatan kerja 7) Undang-undang No. 21 Tahun 2003 tentang Pengesahan Konvensi ILO No. 81.2,3,8

Undang-undang tersebut dilengkapi dengan beberapa peraturan pelaksanaan yang lebih rinci antara lain adalah: 1) Kepres RI No. 22 Tahun 1993 tentang Penyakit yang Timbul akibat Hubungan Kerja. 2) Instruksi Presiden No. 7 Tahun 1999 tentang Wajib Laporan Penyakit Akibat Hubungan Kerja 3) Keputusan Menteri Tenaga Kerja No.Kep333/MEN/1989 tentang Diagnosis dan Pelaporan Penyakit Akibat Kerja 5) Peraturan Menteri Tenaga Kerja dan Transmigrasi No.Per.01/MEN/1981 tentang Kewajiban 
Melapor Penyakit Akibat Kerja. Pemberi kerja wajib melaporkan secara tertulis kepada Direktorat Pimbinaan Hubungan Perburuhan Perlindungan Tenaga Kerja setempat. Penyakit akibat kerja yang wajib dilaporkan ditetapkan dalam lampiran Permen ini, antara lain adalah pneumokoniosis (salah satu PAK paru) dan NIHL. 4) Peraturan Menteri Tenaga Kerja Transmigrasi dan Koperasi No.Per. 03/MEN/1982 tentang Pelayanan Kesehatan Kerja. 6) Keputusan Menteri Kesehatan RI No. 1075/ MENKES / SK/VII/2003, tentang Pedoman Sistem Informasi Manajemen Kesehatan Kerja (SIM-KK). Pemberi kerja diwajibkan melaporkan PAK kepada Dinas Kesehatan Kabupaten/Kota dan Puskesmas Kecamatan. 2,3,8

Dalam melaksanakan pembinaan norma-norma kesehatan kerja, Departemen Kesehatan berfungsi memfasilitasi antara lain dengan cara menetapkan norma, standar serta petunjuk praktis, menyediakan infrastruktur, fasilitas dan sumber daya manusia dalam pelayanan kesehatan kerja terutama di ranah publik. Sedangkan Departemen Tenaga Kerja dan Transmigrasi berfungsi mengawasi pelaksanaannya di lapangan. Selain itu terdapat beberapa departemen teknis lain yang turut mengatur dan mengawasi pelaksanaan $\mathrm{K} 3$ di bidangnya, antara lain Departemen Energi dan Sumber Daya Mineral, Departemen Perhubungan dan Departemen Pekerjaan Umum.

Ilmu dan praktik kesehatan kerja juga secara berkelanjutan dikembangkan oleh akademisi di perguruan tinggi, organisasi profesi seperti IDKI, PERDOKI, AHKKI dan A2K3, serta DK3N. Pemerintah dalam hal ini Direktorat Bina Kesehatan Kerja Departemen Kesehatan, dibantu dan bekerjasama dengan institusi-institusi dan para pakar di bidangnya.

\section{Kesehatan Kerja di Tingkat Perusahaan}

Pemberi kerja wajib menciptakan kondisi dan lingkungan kerja yang sesuai standar, memotivasi pekerja bekerja sesuai standar operating prosedur, menjamin kesehatan, keselamatan dan kesejahteraan pekerja.2,3 Para pekerja yang diharapkan mengalami kepuasan kerja dan hidup berkualitas dapat bekerja secara produktif dan menghasilkan produk/jasa yang berkualitas, bernilai dan menguntungkan. Dengan demikian, perusahaan mampu berkompetisi dan dapat berperan dalam pembangunan nasional secara langgeng dan berkelanjutan. Sebagian pemberi kerja mulai menyadari bahwa masalah K3 secara langsung maupun tidak langsung berpengaruh terhadap biaya operasional perusahaan dan kelangsunan produktivitas sumber daya manusia. Mereka menganggap pelaksanaan kesehatan dan keselamatan kerja merupakan kebutuhan. Para pekerja membutuhkan pekerja yang sehat dan produktif, sehingga mereka menentukan 'kesehatan dan keselamatan' sebagai pilihan. Perusahaan seperti ini dinyatakan telah memiliki budaya K3.

Pada perusahaan formal dengan organisasi manajemen yang baik, Kesehatan Kerja merupakan organisasi struktural yang berdiri sendiri atau bergabung dengan organisasi Keselamatan Kerja menjadi Bagian Kesehatan dan
Keselamatan Kerja (Occupational Health and Safety/OHS), atau Bagian Keselamatan dan Kesehatan Kerja (Occupational Safety and Health/OSH), bahkan bergabung dengan Kesehatan Lingkungan menjadi Bagian Keselamatan, Kesehatan dan Lingkungan (Safety, Health and Evironment) (SHE). Organisasi tersebut biasanya berada dalam pembinaan dan pengawasan Direktur Sumber Daya Manusia atau Direktur Produksi. Infrastruktur pelayanan kesehatan kerja yang bersifat kuratif dan rehabilitatif dapat berada di dalam perusahaan atau di outsourcing. Namun, tidak semua perusahaan formal mempunyai stuktur organisasi K3.7,8,12 Depnakertrans mensyaratkan organisasi fungsional yaitu Panitia Pembina Keselamatan dan Kesehatan Kerja (P2K3) yang merupakan organisasi bipartit di tingkat perusahaan. Anggota P2K3 terdiri dari wakil manajemen dan wakil pekerja dengan komposisi masing-masing $50 \%$ dan diketuai oleh pimpinan tertinggi di tempat kerja. Ketua P2K3 dibantu oleh sekretaris dengan kualifikasi profesional Keselamatan atau Kesehatan Kerja, atau minimal telah mendapatkan pelatihan $\mathrm{K} 3 . \mathrm{P} 2 \mathrm{~K} 3$ berfungsi menangani masalah K3 dengan hasil kerja berupa kebijakan, sistem atau prosedur kerja yang praktis untuk melindungi keselamatan dan kesehatan pekerja. ${ }^{2}$

Departemen Kesehatan melalui Direktorat Bina Kesehatan Kerja telah mengembangkan Pelayanan Kesehatan Kerja Dasar baik bagi perusahaan yang terorganisir maupun dunia kerja dan usaha di ranah publik yang belum terorganisir. ${ }^{13}$ Bagi $80 \%$ pekerja yang bergerak di sektor informal, seperti UMKM, petani, nelayan, pedagang kaki lima dan pekerja sektor lain yang tidak mempunyai akses pelayanan kesehatan kerja formal yang terorganisir di perusahaan, kesehatan kerja dibina oleh Puskesmas dengan pembentukan Pos Upaya Kesehatan Kerja (Pos UKK). Seperti posyandu, Pos UKK adalah upaya kesehatan kerja yang dibentuk dari, oleh dan untuk masyarakat. Pos UKK tersebut dibina oleh Puskesmas dan dibentuk antara lain dengan mekanisme Pengembangan Kesehatan Masayarakat Desa (PKMD).

\section{Konsep Kesehatan Kerja Mikro \\ Hazard, Risiko dan Sistem Kesehatan Kerja}

Dari sudut pandang kesehatan kerja, sistem kerja mikro mencakup empat komponen kerja, yaitu pekerja, lingkungan kerja, pekerjaan, pengorganisasian pekerjaan dan budaya kerja. Setiap komponen kerja mempunyai sumber atau situasi yang berpotensi menimbulkan kerugian bagi kesehatan pekerja. Hal tersebut dapat berupa luka atau gangguan kesehatan. Sumber atau situasi yang potensial tersebut dikenal sebagai hazard atau faktor risiko yang dapat berupa (1) hazards tubuh pekerja (somatic hazards); (2) hazards perilaku kesehatan (behavioural hazards); (3) hazards lingkungan kerja (enviromental hazards) berupa faktor fisik, kimia dan biologik; (4) hazards pekerjaan (work hazards) berupa faktor ergonomik; (5) hazards pengorganisasian pekerjaan (work organization hazards) dan (6) hazards budaya kerja (work culture hazards) berupa faktor psikosial. $4,14,15$ 
Pada kondisi tertentu Hazard kesehatan dapat menjadi nyata dan menimbulkan luka atau gangguan kesehatan. Peluang hazard kesehatan untuk menjadi kenyataan disebut sebagai risiko yang diukur dengan konsekuensi dan peluang kejadian konsekuensi tersebut. Risiko semakin besar jika konsekuensi gangguan kesehatan yang ditimbulkan berat, peluang atau frekuensi kejadian tersebut kerap.

Sistem kesehatan kerja merupakan kegiatan pengendalian risiko kesehatan yang mencakup rekognisi hazard, penilaian risiko dan intervensi risiko. Sistem kesehatan kerja dibangun di atas empat komponen yang sama, dengan melakukan serangkaian upaya kesehatan kerja, agar setiap komponen menjadi sehat Dengan mengenal /rekognisi hazard yang bersumber dari (1) perilaku hidup, perilaku bekerja, kapasitas kerja dan status kesehatan pekerja, (2) lingkungan kerja, (3) pekerjaan, serta (4) pengorganisasian pekerjaan dan budaya kerja. Selanjutnya, menilai besar risiko masing-masing hazard (faktor risiko); dan dilanjutkan dengan intervensi, berupa upaya untuk meniadakan atau meminimalkan risiko yang ditimbulkannya. ${ }^{14,15}$

\section{Ruang Lingkup Kesehatan Kerja}

Kontribusi Kesehatan Kerja dalam sistem kerja yang utama adalah (1) mempertahankan, meningkatkan derajat kesehatan dan kapasitas kerja fisik pekerja; (2) melindungi pekerja dari efek buruk lingkungan, pekerjaan serta pengorganisasian pekerjaan dan budaya kerja. 5,12,14,15

Pelayaan kesehatan kerja yang difokuskan pada upaya promotif dan preventif seperti yang tercantum dalam definsi Komisi Gabungan ILO/WHO pada tahun 1950 dan 1995. Hal tersebut terutama ditekankan pada upaya peningkatan/ promosi dan pencegahan penyakit. Pelaksanaan kesehatan kerja di Indonesia bersifat komprehensif yang mencakup upaya promotif dan preventif serta mencakup pula upaya kuratif dan rehabilitatif (objek empiris ilmu kedokteran kerja). Hal tersebut sesuai dengan kewajiban peraturan perundang-undangan di Indonesia (Permenakertrans \& Koperasi No.Per. 03/Men/1982 tentang Pelayanan Kesehatan Kerja dan UU No. 13 tahun 2003 tentang Ketenagakerjaan). ${ }^{3}$ Pelayanan kesehatan kerja yang komprehensif juga tercantum dalam Basic Occupational Health Services yang diusulkan oleh ICOH tahun 2005.12 Ruang lingkup atau fungsi pokok pelayanan kesehatan kerja yang komprehensif meliputi enam area promotif dan preventif ditambah satu area kuratif dan rehabilitatif. $5,12,14,15$

Pertama, penempatan pekerja pada pekerjaan/jabatan yang sesuai (fit) dengan kapasitas kerja dan status kesehatannya, merupakan upaya preventif. Kesesuaian tersebut adalah keserasian antara status kesehatan, kapasitas dan kapabilitas pekerja secara fisik, mental dan sosial, dengan tuntutan kondisi kerja yang bersumber dari lingkungan, pekerjaan, pengorganisasian pekerjaan dan budaya kerja. Pemeriksaan kesehatan dilakukan sebelum penempatan (pre-placement test), untuk pekerja baru dan pekerja lama yang akan dipindah tu- gaskan. Untuk itu, perlu deskripsi tuntutan tugas (task demand) meliputi data kondisi lingkungan higiene industri, kondisi pekerjaan ergonomi dan kondisi psikososial yang bersumber dari pengorganisasian pekerjaan dan budaya kerja.

Kedua adalah promosi kesehatan di tempat kerja/PKDTK (workplace health promotion) untuk meningkatkan derajat kesehatan dan kapasitas kerja serta pencegahan penyakit, merupakan upaya promotif dan preventif. PKDTK bertujuan untuk mengendalikan faktor risiko yang bersumber dari perilaku, misalnya pola makan, aktivitas fisik, berat badan, konsumsi rokok, alkohol atau narkoba, untuk mencegah penyakit degeneratif seperti penyakit jantung koroner, stroke dan hipertensi. PKDTK adalah ilmu dan seni yang membantu pekerja dan manajemen mengubah perilaku hidup dan perilaku bekerja untuk mencapai kapasitas kerja dan tingkat kesehatan yang optimal, sehingga meningkatkan kinerja. produktivitas dan kapasitas kerja. Di lapangan, PKDTK diaplikasikan sebagai program yang dirancang melalui proses peningkatan pengetahuan, sikap, perilaku dan keterampilan (pendidikan), dari, oleh, untuk dan bersama masyarakat di tempat kerja. Hal tersebut sesuai dengan kondisi dan potensi tempat kerja, dengan pendekatan pendidikan, organisasi, masyarakat lingkungan dan keluarganya, sehingga mampu mengendalikan kesehatan pekerja.

Ketiga adalah perbaikan lingkungan kerja, merupakan upaya preventif. Perbaikan dilakukan dengan mengendalikan berbagai faktor risiko kontaminan fisik, kimia, dan biologi. Faktor risiko fisik meliputi panas, bising, getaran dan radiasi. Faktor risiko kimia antara lain meliputi merkuri, timah hitam, benzene, kloroform, organofosfat dan parakuat. Faktor risiko biologi antara lain meliputi virus HIV/AIDS, leptospirosis dan hepatitis B. Barbagai faktor risiko yang bersumber dari lingkungan kerja tersebut dikendalikan agar tidak melebihi nilai ambang batas yang diperkenankan. Upaya yang kompleks ini telah berkembang menjadi Ilmu Higiene Industri (Industrial Hygiene).

Keempat adalah perbaikan pekerjaan, merupakan upaya preventif. Perbaikan dilakukan dengan menyesuaikan tuntutan tugas dengan kemampuan fisik dan mental pekerja serta mengendalikan faktor risiko ergonomi yang bersumber dari pekerjaan. Sebagai contoh, desain mesin, desain work station, posisi duduk, alat bantu tangan, beban angkat angkut diupayakan agar pekerja terhindar dari postur janggal yang dapat menimbulkan gangguan muskuloskeletal (trauma kumulatif). Upaya yang kompleks ini ini juga telah berkembang menjadi Ilmu Ergonomi (Ergonomy).

Kelima adalah pengembangan pengorganisasian pekerjaan dan budaya kerja merupakan upaya preventif. Pengembangan dilakukan dengan memperbaiki kondisi faktor risiko stres psikososial yang bersumber dari pengorganisasian pekerjaan dan budaya kerja (Work Organization and Work Culture). Sebagai contoh desentralisasi dalam perencanaan tugas, penerapan konsep tugas penuh, otonomi tugas yang masih terintegrasi dengan tujuan ornagisasi yang lebih tinggi tingkatan- 
nya, perbaikan beban kerja, status kepegawaian, sistem pengupahan, gaya manajemen, komunikasi antar pekerja maupun antara pekerja dan pimpinan.

Keenam adalah surveilans kesehatan pekerja, merupakan upaya preventif. Surveilans kesehatan kerja meliputi kegiatan: a) mengumpulkan data faktor risiko kesehatan di tempat kerja yang bersumber dari lingkungan kerja, pekerjaan, pengorganisasian pekerjaan dan budaya kerja; data kesehatan (dari hasil pemeriksaan kesehatan sebelum kerja, berkala dan khusus serta data kunjungan pengobatan/perawatan) dan kemangkiran pekerja; b) melakukan analisis dan interpretasi data berdasarkan kaidah epidemiologi untuk melihat frekuensi, distribusi dan trend perkembangan faktor risiko dan gangguan kesehatan, menilai hubungan faktor risiko dan gangguan kesehatan pekerja; c) komunikasi data dan hasil analisis untuk digunakan dalam rencana perbaikan. Pencatatan dan pelaporan upaya pelayanan kesehatan kerja dan kasus KAK/PAK (secara agregat), dilaporkan kepada manajemen, serikat pekerja dan Dinas Kesehatan, Dinas Tenaga Kerja dan Tansmigrasi. KAK/PAK secara individu (by name) hanya dilaporkan dengan cara yang menjunjung tinggi kode etik untuk kepentingan kompensasi. Dokumentasi termasuk rekam medik dijaga kerahasiaannya dan dipertahankan minimal 30 tahun, bahkan ada yang menganjurkan dipertahankan seumur hidup.

Yang terakhir adalah pelayanan klinik, merupakan upaya kuratif dan rehabilitatif. Pelayanan klinik mencakup diagnosis, terapi, rehabilitasi dan bila diperlukan perhitungan cacat serta rujukan bagi pekerja yang sakit/cedera, serta pelayanan P3K (cedera/penyakit akut), bahkan Medical Emergency Plan yang merupakan upaya preventif.

\section{Kesehatan Kerja dari Perspektif Keilmuan}

Ilmu Kesehatan Kerja adalah bagian dari Ilmu Kesehatan Masyarakat yang sejak awal bertujuan mencegah kematian dini dan penyakit dengan menerapkan ilmu pengetahuan pencegahan penyakit. Dalam perjalanannya, Ilmu Kesehatan Masyarakat sangat memperhatikan pemeliharaan dan peningkatan derajat kesehatan dan kapasitas kerja, dengan menerapkan ilmu pengetahuan promosi kesehatan. Ilmu Kesehatan Kerja bertujuan melindungi (proteksi) pekerja dari penyakit serta meningkatkan derajat kesehatan pekerja dan kapasitas kerjanya. ${ }^{14}$

Fokus kajian Ilmu Kesehatan Kerja dari segi keilmuan, ontologi atau objek empirik adalah kesehatan pekerja, perilaku kesehatan dan hazard/faktor risiko kesehatan di tempat kerja. Kajian kesehatan pekerja meliputi kesehatan fisik dan mental. Perilaku kesehatan adalah faktor risiko perilaku hidup dan perilaku bekerja yang berpotensi menimbulkan risiko penyakit degeneratif dan atau Penyakit Akibat Kerja (PAK) atau Penyakit Terkait Kerja (PTK) pada populasi pekerja. Sedangkan risiko kesehatan di tempat kerja dapat bersumber dari lingkungan, pekerjaan, pengorganisasian pekerjaan dan budaya kerja. Epistemologi atau metode pokok yang digu- nakan adalah melakukan proses perbaikan berkelanjutan, dengan pengenalan, analisis, pengendalian dan evaluasi faktor risiko penyakit degeneratif dan PAK/PTK (termasuk gangguan trauma kumulatif). Aksiologi atau manfaatnya adalah pencegahan kerugian akibat penyakit degeneratif dan PAK/PTK, sehingga meningkatkan derajat kesehatan dan kapasitas kerja. ${ }^{14,15}$

Sesuai kebutuhan dalam penerapannya, Ilmu Higiene Industri dan Ilmu Ergonomi berkembang pesat. Kedua ilmu tersebut besama Ilmu Kesehatan dan Ilmu Perilaku merupakan inti ilmu kesehatan kerja yang didukung oleh berbagai ilmu lain seperti ilmu kedokteran penyakit dan cedera pekerja, toksikolgi industri, epidemiologi, statistik, manajemen, pendidikan dan pelatihan, komunikasi dan informasi, sosial dan budaya. Selain itu, ilmu kesehatan kerja juga didukung oleh ilmu-ilmu dasar antara lain adalah ilmu fisika, kimia, biologi, fisiologi, psikologi, hukum, politik dan ekonomi.

\section{Pengertian}

Definisi kesehatan kerja mengacu pada Komisi Gabungan ILO/WHO dalam Kesehatan Kerja pada tahun 1950 yang direvisi pada sesi ke-12 tahun $1995 .{ }^{5}$ Kesehatan kerja adalah upaya mempertahankan dan meningkatkan derajat kesehatan fisik, mental dan kesejahteraan sosial semua pekerja yang setinggi-tingginya. Mencegah gangguan kesehatan yang disebabkan oleh kondisi pekerjaan; perlindungan pekerja dari faktor risiko pekerjaan yang merugikan kesehatan. penempatan dan pemeliharaan pekerja dalam suatu lingkungan kerja disesuaikan dengan kapabilitas fisiologi dan psikologinya, dan disimpulkan sebagai adaptasi pekerjaan kepada manusia dan setiap manusia kepada pekerjaannya. Fokus utama upaya Kesehatan Kerja mencapai tiga tujuan: 1) Pemeliharaan dan peningkatan derajat kesehatan pekerja dan kapasitas kerjanya 2) Perbaikan kondisi lingkungan kerja dan pekerjaan yang kondusif bagi K3 3) Pengembangan pengorganisasian pekerjaan dan budaya kerja ke arah yang mendukung K3. Juga meningkatkan kondisi sosial yang positif dan operasi yang lancar dan dapat meningkatkan produktivitas perusahaan. Konsep budaya kerja yang dimaksudkan dalam kerangka ini adalah refleksi sistem nilai pokok yang diadopsi oleh perusahaan tertentu. Budaya yang demikian itu diwujudkan dalam praktek sebagai sistem manajemen, kebijakan personalia, prinsip partisipasi, kebijakan pelatihan dan manajemen mutu perusahaan.

Di Indonesia, dalam Undang-Undang no.23 /1992 tentang Kesehatan pasal 23 disebutkan bahwa Kesehatan Kerja bertujuan untuk mewujudkan produktivitas kerja yang optimal. Cara mencapainya meliputi pelayanan kesehatan kerja, pencegahan penyakit akibat kerja dan syarat kesehatan kerja. Pasal 84 mengatur tentang sanksi pidana bagi yang tidak melaksanakan. ${ }^{3}$ Definisi Kesehatan ini akan disempurnakan dalam revisi undang-undang tersebut yang saat ini masih dalam proses. 


\section{Kesehatan Kerja dalam Praktik}

Definisi Kesehatan Kerja di atas menyiratkan pemeliharaan dan peningkatan kesehatan pekerja agar tidak sakit, jauh lebih luas daripada sekedar menyembuhkan penyakit. Membina kesehatan masyarakat pekerja dan menciptakan pekerja yang sehat dan produktif, tidak bisa dilaksankan hanya dengan pendekatan kedokteran. Untuk itu, perlu dilakukan pendekatan holistik, multi sektor, dan release approach yaitu menciptakan pekerja yang sehat, produktif, mandiri dalam menjaga kesehatan. Para pekerja diharapkan lebih tahan terhadap penyakit, tidak tergantung pada obat dan pelayanan medis yang bersifat kuratif; membetulkan, memperbaiki atau mengembalikan sesuatu yang telah terjadi. ${ }^{16}$

Di Indonesia, praktik Kesehatan Kerja mulai berjalan secara lebih terarah pada beberapa perusahaan besar sejak UU No.1 tahun 1970 tentang Keselamatan Kerja diberlakukan. Sebagian besar pekerja UMKM di sektor formal atau informal tidak terakses kesehatan kerja. Pelaksanaan di perusahaan formal sangat bervariasi mencakup (1) sangat sederhana berupa P3K untuk menangani pekerja yang mengalami kecelakaan kerja atau penyakit akut. Dengan demikian, hanya melaksanakan upaya kuratif dan rehabilitaf, terutama di perusahaan besar; 2) upaya komperhensif mencakup promotif, preventif, kuratif dan rehabilitatif sesuai dengan yang dipersyaratkan oleh Peraturan Menteri Tenaga Kerja dan Transmigrasi R.I. No. Per.03/Men/1982, pasal 2 dan diusulkan oleh ICOH tahun 2005; (3) sebagian kecil mulai mengoutsource upaya kuratif dan rehabilitatif dan fokus menjalankan fungsi promosi dan prevensi sesuai yang dirumuskan oleh Komisi Gabungan ILO dan WHO tahun $1995 .^{5}$

Pada praktik di lapangan, pengandil (stakeholders) kesehatan kerja meliputi pekerja dan wakilnya (serikat pekerja), manajemen atau pemilik usaha, dan pemerintah. Komponen pemerintah meliputi Depertemen Kesehatan, Depertemen Tenaga Kerja dan Transmigrasi, Departemen Energi dan Sumber Daya Mineral serta instansi teknis terkait lainnya, selain itu termasuk juga akademisi dan asosiasi profesi.

Isu terkini dalam praktik kesehatan kerja di Indonesia antara lain meliputi perkembangan 1) kebutuhan peningkatan koordinasi dan sinergi antar pengandil 2) kebutuhan pada harmonisasi peraturan perundang-undangan dan sistem informasi/ pelaporan kepada instansi terkait yang lebih terarah dan tidak tumpang tindih. 3) kebutuhan dukungan pemerintah dalam penegakkan kewajiban dan penegakkan hukum (law enforcement), serta dukungan sumber daya manusia dan fasilitas (capacity building) dalam pelaksanaan kesehatan kerja di dunia usaha dan dunia kerja. 4) kebutuhan standar kompetensi profesi Kesehatan Kerja untuk menjamin mutu pelayanan. 5) konsep dosis pajanan. Praktisi membutuhkan nilai ambang batas pajanan toksikan atau substansi lainnya yang berada di lingkungan kerja, agar pekerja tidak terkena dampak kesehatan. 6) rekognisi hubungan antara tugas atau pekerjaan tertentu dengan status kesehatan atau penyakit. Misalnya pengemudi taksi dengan penyakit nyeri punggung bawah (low back pain). 7) studi epidemiologi yang menentukan hubungan antara penyakit dan faktor risiko. ${ }^{10}$

\section{Profesi Kesehatan Kerja}

Kesehatan Kerja bersifat multidisiplin. Pelaksanaan upaya kesehatan kerja yang berbasis komunitas memerlukan koordinasi serta kerja sama antar profesi dari berbagai disiplin il$\mathrm{mu}$, antara lain dokter, engineer, industrial higienist, ahli ergonomi, safety engineer (ahli keselamatan kerja), ahli faal, kimia, fisika, kesehatan masyarakat, sosiologi, psikologi, pendidikan, hukum dan manajemen. Hal tersebut berbeda dengan Kedokteran Kerja atau Occupational Medicine yang merupakan bagian dari ilmu kedokteran dan berbasis klinik yang hanya dikerjakan oleh dokter dan paramedis, Kesehatan Kerja adalah ilmu multidisiplin yang memerlukan koordinasi dan kerja sama berbagai profesi. ${ }^{4,5,12,17}$

Dokter perusahaan sebagai salah satu anggota dari tim kesehatan kerja, dituntut memiliki pengetahuan yang lebih luas dari sekedar ilmu kedokteran. Dengan demikian, mereka dapat bekerja sama dengan profesi lain guna mempertahankan dan meningkatkan kesehatan pekerja. Hal tersebut antara lain dilakukan dengan menyusun program kesehatan sesuai kebutuhan dan mampu memimpin pelaksanaannya. Diagnosis dan terapi penyakit umum dan PAK/PTK merupakan bagian dari ilmu kedokteran kerja yang selayaknya dilaksanakan oleh dokter. Upaya proteksi, pencegahan dan promosi perilaku hidup sehat dan bekerja sehat yang dilakukan terhadap pekerja, bertujuan agar pekerja tidak terkena penyakit umum dan PAK/PTK. Hal tersebut merupakan bagian penting dari tanggung jawab profesi Kesehatan Kerja yang terlibat secara langsung atau tidak langsung berasal dari berbagai latar belakang dengan pembagian tugas, antara lain meliputi:

Pertama, upaya pencegahan penyakit dengan penempatan pekerja, surveilans medis, diagnosis dini, terapi segera, rehabilitasi dan kompensasi. Dokter Kesehatan Kerja dan dokter terlatih Dasar Kesehatan Kerja selama 10 minggu merupakan tenaga kesehatan terdepan untuk diagnosis dan terapi Perawat terlatih tentang Dasar Kesehatan Kerja selama 10 minggu, membantu dokter untuk mencatat riwayat pekerjaan/tugas dan riwayat pajanan, data surveilans efek kesehatan akibat pajanan faktor risiko, terapi dan rehabilitasi pekerja yang menderita PAK/PTK. ${ }^{12}$ Dokter Spesialis Okupasi dan Dokter Kesehatan Kerja pendidikan strata II) merupakan konsulen, employment medical advisor dan peneliti/pengembang ilmu. Dokter Penasehat (versi Depnaker) bertanggung jawab bila terjadi keraguan penetapan cacat dan kompensasi KAK/ PAK/ PTK.2,3

Kedua, Untuk mencegah kejadian PAK/PTK dilakukan perbaikan lingkungan, pekerjaan, pengorganisasian pekerjaan dan budaya kerja oleh higyenist, ergonomis, psikologi industri dan profesi manajemen sumber daya manusia. Penilaian dan talaksana risiko kesehatan dilakukan sesuai bidang masingmasing. Penilai efek hazard yang bersumber lingkungan, pekerjaan, pengorganisasian pekerjaan dan budaya kerja meli- 
batkan dokter. ${ }^{4,5,12}$

Ketiga, Promosi perilaku dan bekerja sehat dilakukan oleh tim yang terdiri dari dokter, psikolog, safety engineer dan perawat (fasilitator), personalia (motivator), wakil manajemen (penentu kebijakan), wakil serikat pekerja (peers educator), dan trainers yang terlatih (eksekutor).5,7,12,15

\section{Etika Kesehatan Kerja}

Pelaksanaan upaya kesehatan kerja dengan subjek manusia tersebut memerlukan etika, karena ada unsur HAM yang harus dihormati dan dijaga. Etika kesehatan kerja tidak persis sama dengan etika kedokteran, karena: (1) tanggung jawab profesi kesehatan kerja yang kompleks terhadap pekerja, pemberi kerja, lembaga terkait kesehatan masyarakat, kesejahteraan sosial dan hukum; (2) profesi kesehatan kerja terdiri dari banyak individu yang berasal dari berbagai disiplin ilmu; dan (3) pendekatan multidisiplin dengan latar belakang yang bervariasi.

Di Indonesia, kode etik yang terkait dengan kesehatan kerja telah disusun oleh beberapa organisasi profesi, antara lain: 1) Kode Etik Dokter Kesehatan Kerja disusun IDKI (1999). ${ }^{18}$ 2) Kode Etik Spesialis Kedokteran Okupasi disusun PERDOKI (2004). ${ }^{19}$ 3) Di tingkat internasional, kode etik pertama profesi kesehatan kerja dipublikasi oleh ICOH pada tahun 1992 dan direvisi pada tahun 2002. ${ }^{20}$ Kode etik ini relevan bagi profesional yang bertugas di perusahaan, sektor swasta/ umum, berkaitan dengan K3, higiene dan lingkungan kerja. Kode etik tersebut juga berlaku bagi individu/organisasi pelayanan K3 terhadap pelanggan dan dalam pelayanan kesehatan masyarakat atau komersial.

Prinsip etika dan nilai dalam kode etik ICOH tersebut mencakup: 1) Kesehatan kerja bertujuan memberikan pelayanan kesehatan dan kesejahteraan sosial bagi pekerja, individu atau kelompok. Praktik kesehatan kerja harus berdasarkan standar tertinggi profesi dan prinsip etika. 2) Kebijakan dan program kesehatan kerja melindungi kehidupan \& kesehatan pekerja, menjunjung HAM dan etika Berintegritas, tidak apriori, menjaga kerahasiaan data dan privacy pekerja. 3) Bebas berkarya sebagai ahli dalam menjalankan fungsi kesehatan kerja. Mendapatkan dan menjaga kompetensi serta kondisi yang diperlukan dalam menjalankan tugas sesuai praktik yang baik dan etika profesi.

\section{Kesimpulan}

Upaya kesehatan kerja harus dilaksanakan di dunia usaha atau dunia kerja, di sektor formal maupun informal. Pemberi kerja pemerintah dan swasta bertanggung jawab atas pekerjaan yang layak dan perlindungan kesehatan pekerjanya. Upaya tersebut dilakukan berdasarkan hazard atau faktor risiko yang mungkin timbul dari perilaku dan status kesehatan pekerja, lingkungan kerja, pekerjaan, serta pengorganisasian pekerjaan dan budaya kerja. Untuk itu, sudah saatnya meninggalkan praktik kesehatan yang hanya mengobati dan memulihkan pekerja yang sakit. Profesi kesehatan kerja di- tuntut mengambil tanggung jawab memberikan pelayanan kesehatan yang komprehensif yang meliputi upaya pencegahan dengan menempatkan pekerja pada tempat yang sesuaian dengan status kesehatan, kapasitas kerja dan tuntutan tugas. Memelihata dan meningkatkan derajat kesehatan melalui upaya promosi kesehatan, perbaikan lingkungan dan pekerjaan dengan upaya higiene industri dan ergonomi, serta mengembangkan pengorganisasian pekerjaan dan budaya kerja yang kondusif bagi kesehatan pekerja.

\section{Daftar Pustaka}

1. Taylor RF, Pickvance S. Resouces, institutional, structural and legal. In: Stellman JM, editor. Encyclopedia of occupatinal health and safety. $4^{\text {th }}$ ed. Geneva: ILO; 1998.

2. Pungky W. Peraturan keselamatan dan kesehatan kerja. Jakarta: Depnakertrans; 2004.

3. Yanri Z. Himpunan peraturan perundangan kesehatan kerja. Jakarta: Lembaga ASEAN OSHNET Indonesia; 2005.

4. Taylor G, Easter K, Hegney R. Enhancing occupational safety and health. Amsterdam: Elsevier; 2004.

5. Fedotov IA, Saux M, Rantanen J. Occupational Health Services, In: Stellman JM, editor. Encyclopedia of occupatinal health and safety. $4^{\text {th }}$ ed. Geneva: ILO; 1998.

6. Yayasan Jantung Indonesia. Kardiovaskuler dapat dihindari! Institusi. http://id.inaheart.info [11 Maret 2006].

7. Sukardi MG. Evaluasi program pengendalian berat badan berlebih di Pertamina unit pemasaran IV Semarang tahun 2005, [tesis]. Jakarta: Univ. Indonesia; 2006.

8. Kurniawidjaja LM. Penyakit akibat kerja dan rekomendasi manajemen risiko kesehatan di Indocement pabrik Citeureup. Jakarta: Indocement; 2006.

9. Parker J, editor. Summary. Proceedings of the 10th International Conference on Occupational Respiratory Diseases; 2005 Apr 19-22; Beijing, China.

10. Dewan Keselamatan dan Kesehatan Kerja Nasional. Rapat pleno DK3N 2007. Jakarta: Institusi; 2007.

11. Dewan Keselamatan dan Kesehatan Kerja Nasional. Rapat pleno DK3N 2007. Jakarta: Institusi; 2006.

12. International Commission on Occupational Health. Basic occupational health services. ICOH; 2002.

13. Departemen Kesehatan RI. Pedoman pelayanan kesehatan kerja pada Puskesmas kawasan/sentra industri. Keputusan Menteri Kesehatan RI Nomor: 038/MENKES/SK/I/2007. Jakarta: Direktorat Bina Kesehatan Kerja. 2007.

14. Martomulyono S. Bahan kuliah Dasar-Dasar Keselamatan dan Kesehatan Kerja. Depok: Departemen Keselamatan dan Kesehatan Kerja FKM-UI; 2006.

15. Kurniawidjaja LM. Modul kuliah Kesehatan Kerja. Depok: Departemen Keselamatan dan Kesehatan Kerja FKM-UI; 2007.

16. Seaton A, Agius R, McCloy E, D’Auria D. Practical occupatinal medicine. London: Edward Arnold; 1994.

17. Levy BS, Wegman DH. Ocupational health, an overview. In: Levy BS, Wegman DH, editors. Occupational health. 4th ed. Philadelphia: Lippincott Williams \& Wilkins; 2000.

18. Perhimpunan Dokter Kesehatan Kerja Indonesia. Kode Etik Dokter Kesehatan Kerja. Prigen: IDKI 1999.

19. Perhimpunan Spesialis Kedokteran Kerja Indonesia. Kode Etik Spesialis Kedokteran Okupasi. Jakarta: PERDOKI. 2004.

20. International Commission on Occupational Health. International code of ethics for occupational health professionals. ICOH. 2002. 